\title{
Erratum: Allergenicity assessment of genetically modified crops—what makes sense?
}

Richard E Goodman, Stefan Vieths, Hugh A Sampson, David Hill, Motohiro Ebisawa, Steve L Taylor \& Ronald van Ree

Nat. Biotechnol. 26, 73-81 (2008); published online 8 January 2008

In the version of this article initially published, the DOI was incorrect. The error has been corrected in the HTML and PDF versions of the article.

\section{Erratum: Europe's anti-GM stance to presage animal feed shortage?}

Peter Mitchell

Nat. Biotechnol. 25, 1065-1066 (2007); published online October 2007

In the version of this article initially published, on page 1066, paragraph 3, Moisés Burachik was quoted as saying, "EFSA [the European Food Safety Agency] is not handling approvals in a scientific way." The author misunderstood the speaker, whose point is better represented by, "The EU should start listening to its own scientists."

\section{Corrigendum: Therapeutic targeting of a stem cell niche}

Gregor B Adams, Roderick P Martin, Ian R Alley, Karissa T Chabner, Kenneth S Cohen, Laura M Calvi, Henry M Kronenberg \&

David T Scadden

Nat. Biotechnol. 25, 238-243 (2007); published online 21 Jan 2007; corrected after print 7 February 2008

In the version of this article initially published, the $y$-axes of Figures 1e, 2c and $2 \mathrm{~d}$ are labeled incorrectly. They should be labeled " $\%$ CD45.2 in PB," and not "\% CD45.1 in PB" as labeled originally and in a subsequent corrigendum in August 2007. The error has been corrected in the HTML and PDF versions of the article. 